\title{
A HISTÓRIA SE FAZ PRESENTE: A INFLUÊNCIA DOS DIALETOS ITALIANOS NA FALA EM PORTUGUÊS DE JOVENS ESTUDANTES DO OESTE DE SANTA CATARINA ${ }^{1}$
}

\author{
THE HISTORY IS PRESENT: THE INFLUENCE OF ITALIAN DIALECTS \\ ON THE YOUNG STUDENTS' SPEECH IN PORTUGUESE \\ FROM THE WEST OF SANTA CATARINA
}

\author{
Marizete Bortolanza Spessatto | Lattes | spessatto.mari@gmail.com \\ Instituto Federal de Santa Catarina
}

Resumo: Este trabalho apresenta resultados de uma pesquisa que teve como foco a análise da variação linguística que caracteriza a interferência de uma língua de imigração na fala em português. Trata-se da interferência dos dialetos italianos, sobretudo o vêneto (também chamado de talian, em cenário brasileiro) e se evidencia especialmente por um fenômeno de variação fonológica, com a produção de tepe em contextos de vibrante múltipla, levando à produção de "caro" quando o esperado seria "carro". Partindo de estudos anteriores sobre o tema, delimitou-se a análise a um grupo de 20 falantes jovens, sendo eles estudantes de anos finais do ensino fundamental (idade entre 12 e 16 anos, no período de desenvolvimento da pesquisa). Como base teórica, seguimos os preceitos da Teoria da Variação, também chamada de Sociolinguística Quantitativa. Os resultados da pesquisa, com a análise quantitativa dos dados linguísticos, por meio do programa estatístico VARBRUL (PINTZUK, 1988), mostraram uma acentuada variação na fala dos estudantes, que produziram tepe em $76 \%$ dos contextos de vibrante múltipla tanto em início de palavra, como em "Roma”, quanto em posição intervocálica de vibrante múltipla, como em "terra". Os dados evidenciam a manutenção desse fenômeno em variação, já identificado em pesquisas desenvolvidas a partir dos anos de 1980, mesmo se tratando de sujeitos jovens, a maior parte deles não-detentora da língua de origem do seu grupo étnico.

Palavras-chave: Variação linguística. Línguas de imigração. Educação.

Abstract: This paper presents the results of a research that focused on the analysis of linguistic variation that characterizes the interference of Italian dialects from Veneto as an immigration language, also called Talian in a Brazilian scenario, in Brazilian Portuguese 
speech. $\mathrm{s}$ It is evidenced especially by a phenomenon of phonological variation with the production of tepe in contexts of multiple vibrant, leading to the production of the word "caro" when the expected word would be "carro". Based on previous studies on the subject, the study delimited the analysis in a group of 20 young speakers, students of final years of elementary school (age between 12 to 16 years, in the period of the research development). As a theoretical basis for the study, we follow the precepts of the Theory of Variation or Quantitative Sociolinguistics. The research results, with the quantitative analysis of the linguistic data, through the VARBRUL statistical program (PINTZUK, 1988), showed a marked variation in the students' speech, who produced tepe in $76 \%$ of the contexts of vibrant multiple both in the beginning of the word, as in "Roma", and in the intervocalic position of multiple vibrant, as in "terra". The data show the maintenance of this phenomenon in variation, already identified in research developed since the 1980s, even in the case of young subjects, most of them non-native speakers of the language of their ethnic group.

Keywords: Linguistic variation. Immigration languages. Education.

\section{Considerações iniciais}

Desde a década de 1980, grupos de pesquisadores brasileiros (especialmente FROSI, 1987a, 1987b, 2001; FROSI; MIORANZA, 1983, 2009; MARGOTTI, 2004) e italianos (como BALHANA, 1987; BERETTA, 1987; CORRÀ, 2001, 2003; COSTA; DE BONI, 1991; FRANZINA, 1987; LO CASCIO, 1987; PETRONE, 1991) têm intensificado as pesquisas acerca das características que mais definem as interferências dos dialetos italianos na fala em português brasileiro ${ }^{2}$. Um fenômeno comum identificado por essas pesquisas e que mais caracteriza o grupo é a não produção da vibrante múltipla em contextos esperados, tanto em início de palavras, como em "rua", quanto em posição intervocálica, como em "carro" (FROSI; MIORANZA, 1983, p. 334). Estudos desenvolvidos por Gerhard Rohlfs, na década de 1960, revelam que os dialetos do norte da Itália não possuem a vibrante geminada: "Conforme as características gerais do desenvolvimento fonético setentrional, em toda a Itália setentrional rr sofre a lenização em $r$ (tèra, guèra)”. (ROHFS, 1966, p. 336 apud FROSI; MIORANZA, 1983, p. 347). E, ainda, em um estudo sobre os dialetos vênetos, Zamboni (1974) afirma que: "No que diz respeito, enfim, a /r/, tem-se, em geral, uma vibrante simples apicodental, enquanto o standard possui uma vibrante múltipla” (ZAMBONI, 1974, p. 14 apud FROSI; MIORANZA, 1983, p. 347). 
Essas marcas da interferência dos dialetos italianos na fala em português acompanharam os novos movimentos migratórios por eles feitos para diversos municípios da região oeste de Santa Catarina, na qual se localiza Chapecó ${ }^{3}$, comunidade em estudo neste trabalho. Pesquisas vinculadas ao Varsul - Variação Linguística do Sul do Brasil, com dados coletados nas décadas de 1980 e 1990, contribuíram com análises sistemáticas da fala desses sujeitos. O estudo de Spessatto (2001) mostra que, do total de ocorrências em contextos de vibrante múltipla (início de palavra e posição intervocálica) das 24 entrevistas catalogadas por esse banco de dados, $46 \%$ foram de tepe, $35 \%$ de intermediária ${ }^{4}$ e apenas $19 \%$ foram de vibrante múltipla em contextos esperados.

Como os informantes do Varsul têm idade acima de 25 anos, o trabalho que deu origem a este artigo teve como objetivo identificar a presença desse fenômeno em variação em grupos de sujeitos mais jovens. Também se optou pelo desenvolvimento da pesquisa em contexto escolar, procurando identificar se há interferência da escola na manutenção ou afastamento das características linguísticas em análise. Depoimentos empíricos e dados coletados em pesquisas com o grupo étnico em estudo mostram que muitos pais deixaram de ensinar a língua de imigração aos filhos para "não atrapalhar na escola". Esses depoimentos, é sabido, têm raízes históricas em eventos políticos, em campanhas de desestímulo às línguas estrangeiras ${ }^{5}$, mas também evidenciam o desejo dos pais de que os filhos sejam detentores da "língua de prestígio", especialmente quando esperam que ela oportunize ascensão social.

A importância de estudos acerca do fenômeno em variação linguística que caracteriza o grupo e que se coloca em destaque neste trabalho também leva em consideração o estigma social que foi, ao longo da história, originando um “[..] sentimento de vergonha do ítalo-brasileiro em relação ao seu modo de falar, seja em língua italiana ou em português regional. O sentimento de vergonha do seu próprio modo de falar constitui um estigma sociolinguístico que passa a fazer parte da história de vida de muitos ítalo-brasi-

${ }^{3}$ A cidade tem no início do século XX a sua mais importante marca. Foi o período da chegada dos gaúchos que vieram para a região em busca de novas expectativas de vida. $\mathrm{O}$ fenômeno é chamado de movimento migratório interno, já que a maior parte desses eram imigrantes ou descendentes de imigrantes europeus, a maioria de etnia italiana que, ao chegar no Rio Grande do Sul, já encontraram as terras gaúchas bastante povoadas e então vieram ao oeste catarinense, dando origem às características étnicas e linguísticas aqui analisadas.

4 A produção do fonema foi assim classificada e é mantida neste trabalho por não se tratar nem da realização de um tepe e nem de uma vibrante múltipla, mas uma produção "intermediária”. Frosi e Mioranza (1983) também identificaram a presença de um fonema "intermediário" em pesquisas desenvolvidas na chamada Região de Colonização Italiana (RCI) do Rio Grande do Sul (FROSI; MIORANZA, 1983).

5 Não entraremos nas questões políticas que levaram a um afastamento das línguas de imigração que vieram ao Brasil, especialmente a Campanha de Nacionalização da década de 1930, por não ser o foco deste trabalho. 
leiros" (FROSI, 2001, p. 256).

Como orientação metodológica, seguimos os preceitos da Teoria da Variação, também chamada de Sociolinguística Quantitativa e que tem, no rigor de sua metodologia, uma de suas principais características. A abordagem laboviana se vale do envelope da variação, que consiste na descrição detalhada das variantes de uma regra variável e de seus possíveis condicionamentos. Os procedimentos metodológicos numa pesquisa variacionista consistem em: identificar fenômenos variáveis de uma dada língua; inventariar suas variantes definindo as variáveis dependentes; formular hipóteses que captem as tendências sistemáticas da variação; operacionalizar essas hipóteses mediante o estabelecimento de variáveis independentes (ou grupos de fatores) de natureza linguística e social; identificar, selecionar e codificar os dados relevantes; submeter esses dados a tratamento estatístico adequado; interpretar os resultados quantitativos à luz das hipóteses levantadas (OLIVEIRA E SILVA; SCHERRE, 1996). Considerando esses objetivos e preceitos, seguimos para a análise do fenômeno em estudo.

\section{Variação linguística em contexto escolar: análise das produções dos estudantes em contextos de vibrante múltipla e de tepe}

Para a coleta de dados da pesquisa que resultou neste artigo, desenvolvemos um estudo longitudinal, acompanhando uma turma de sétimo/oitavo ano ao longo de 2008 e 2009 (em 2009 o grupo encerrou as atividades na escola, concluindo o ensino fundamental). Os estudantes da turma em análise, 20 no total, tinham, durante o período da coleta de dados, idades entre 12 e 16 anos. Nove deles viviam em uma mesma comunidade rural e os demais em dois bairros da periferia da cidade, vizinhos à escola onde estudavam. Em relação à etnia, nove indicaram ser filhos de pai e mãe italianos, treze de pais italianos, treze de mães italianas e apenas quatro apontaram não pertencer a esse grupo étnico, indicando ascendência étnica alemã, russa, polonesa e negra. Na análise proposta, consideramos a distinção entre italianos e não-italianos. A separação foi feita para permitir a verificação, na análise quantitativa dos dados, da interferência ou não da etnicidade na produção do fonema vibrante ou, por outro lado, da interferência da fala desse grupo sobre os demais.

Tendo a escola como espaço de pesquisa, procuramos apresentar dados que permitem traçar um perfil da variação sociolinguística dos estudantes concluintes do ensino fundamental, em relação à produção característica da fala local, ou seja, a variação no emprego do fonema vibrante em contextos de vibrante múltipla ("rua" e "carro") e de 
tepe ("parede"). Os dados linguísticos foram retirados de entrevistas gravadas individualmente com os estudantes do nível de ensino descrito, em dezembro de 2009. As 20 entrevistas seguiram um roteiro pré-definido que permitiu a coleta de dados em três contextos estilísticos diferentes: relatos do cotidiano, leitura de texto e avaliação da fala ${ }^{6}$. O primeiro contexto caracterizou-se pelos relatos dos estudantes acerca do cotidiano escolar, a expectativa com o ingresso no ensino médio e, consequentemente, entrada em uma nova escola. Para a coleta de dados em contexto estilístico de leitura, foi apresentado um texto de Cecília Meireles ( $O$ menino dos ff e rr). O contexto de avaliação da fala caracterizou-se pela solicitação, ao final das entrevistas, de que os estudantes analisassem o próprio modo de falar e o da comunidade, a partir das diferenças de produção do fonema vibrante ("carro" e "caro"), questões que foram articuladas à leitura do texto. Consideramos que, com a mudança de contextos estilísticos, conseguimos seguir uma "[...] gama de estilos usados pelo falante rumo ao extremo formal do espectro, onde se presta mais atenção à fala. Há perguntas que naturalmente evocam a fala mais monitorada (como perguntas sobre a própria fala em si)" (LABOV, 2008 [1972], p. 247).

Com a inserção da variável contexto estilístico da entrevista, foi possível controlar, também, se a mudança de estilo apresentou algum tipo de interferência sobre a produção de tepe em contextos de vibrante múltipla e, por outro lado, de vibrante múltipla em contextos de tepe. Em relação às variáveis extralinguísticas, controlamos a influência das variáveis sexo, monolinguismo/bilinguismo e local de moradia (rural/urbano) na produção da vibrante. Apresentamos, no Quadro 1, a estratificação social dos informantes, com o objetivo de ilustrar a distribuição desses de acordo com as variáveis extralinguísticas:

Quadro 1 - Distribuição dos informantes de acordo com as variáveis extralinguísticas

\begin{tabular}{|l|rr|rr|c|}
\hline & \multicolumn{2}{|c|}{ Rural } & \multicolumn{2}{|c|}{ Urbano } & Total \\
\hline & F & M & F & M & \\
\hline Bilíngues (português/dialeto) & 3 & 4 & 2 & 1 & 10 \\
\hline Monolíngues (português) & 0 & 2 & 2 & 6 & 10 \\
\hline Total & 3 & 6 & 4 & 7 & 20 \\
\hline
\end{tabular}

Fonte: Spessatto (2011, p. 53).

Com essa distribuição, perdemos a homogeneidade em relação à variável sexo, somando-se 7 informantes do sexo feminino e 13 do sexo masculino. Também não há uma distribuição homogênea entre informantes residentes na área rural (9) e urbana (11). Porém, tem-se o mesmo número de informantes bilíngues (10) e monolíngues (10). 
Considerando essa caracterização, foram controladas:

variáveis extralinguísticas: local de moradia (rural/urbano); bilinguismo (monolíngues/bilíngues), sexo (masculino/feminino);

variáveis linguísticas: posição na palavra (início de palavra, posição intervocálica em contexto de vibrante múltipla, posição intervocálica em contexto de tepe);

contexto estilístico da entrevista: relatos do cotidiano, leitura e avaliação da fala.

Em relação à variável dependente (o fonema vibrante), controlamos as produções da vibrante múltipla, do tepe e da "vibrante intermediária”. Consideram-se como "intermediárias” as produções do fonema nas quais a vibração não ocorre com o ápice da língua nos alvéolos, como na realização da vibrante, mas sim com a lâmina da língua, em uma situação que não ocorre com a vibrante no sistema fonológico do português-brasileiro. Pode-se interpretar essas realizações como tentativas do informante de produzir uma vibrante múltipla, um esforço para incorporar o traço do sistema fonológico do português em sua fala (SPESSATTO, 2001).

Como já afirmamos, os dados linguísticos coletados por meio das entrevistas foram analisados a partir da análise quantitativa proporcionada pelo programa estatístico VARBRUL (PINTZUK, 1988). Iniciamos a análise quantitativa com a rodada geral que mostra a distribuição das variantes em relação à produção total em contextos de vibrante múltipla e de tepe.

Tabela 1 - Distribuição das realizações do fonema vibrante em início de palavra e posição intervocálica em contextos de vibrante múltipla e de tepe

\begin{tabular}{|c|c|c|c|c|c|c|c|}
\hline Contextos esperados & Vibrante & litipla & Interr & & Tep & & Total \\
\hline Início de palavra (rua) & $\begin{array}{l}\text { Freq. } \\
25 / 140\end{array}$ & $\begin{array}{l}\% \\
18\end{array}$ & $\begin{array}{l}\text { Freq. } \\
3 / 140\end{array}$ & $\begin{array}{r}\% \\
2\end{array}$ & $\begin{array}{l}\text { Freq. } \\
112 / 140\end{array}$ & $\begin{array}{l}\% \\
80\end{array}$ & 140 \\
\hline $\begin{array}{l}\text { Intervocálica em contextos } \\
\text { de vibrante múltipla (carro) }\end{array}$ & $99 / 389$ & 25 & $4 / 389$ & 1 & $286 / 389$ & 74 & 389 \\
\hline $\begin{array}{l}\text { Total contexto de vibrante } \\
\text { múltipla }\end{array}$ & 124 & 23 & 7 & 1 & 398 & 75 & 529 \\
\hline $\begin{array}{l}\text { Intervocálica em } \\
\text { contextos de tepe (parede) }\end{array}$ & 11 & 2 & 0 & 0 & 561 & 98 & 572 \\
\hline TOTAL & 135 & 12 & 7 & 1 & 959 & 87 & 1.101 \\
\hline
\end{tabular}

Fonte: Spessatto (2011, p. 149). 
Fazendo uma análise geral, tem-se 1.101 dados, sendo 529 em contextos esperados de /R/ e 572 em contextos esperados de /r/. Porém, em relação às produções, 959 ocorrências $(87 \%)$ foram de /r/ e 135 (12\%) de /R/. Em relação à intermediária, somou apenas $1 \%$ das ocorrências, com sete produções, todas em contextos esperados de /R/.É em contextos de vibrante múltipla (início de palavra, como em “rua”, e posição intervocálica, como em "carro") que a variação que constitui o grupo é empregada de forma mais significativa: em $\mathbf{7 5 \%}$ desses contextos os informantes produziram tepe (398 ocorrências), em casos como:

"Eu moro na área rural [rural] e não falo nada” $\left(\mathrm{Ana}^{7}\right)$.

“Conseguir meu terreno [tereno], minha casa, meu carro [caro]" (Carlos).

Como já apontamos, a intermediária foi registrada em apenas $1 \%$ das produções em contexto de vibrante múltipla, nos casos listados abaixo:

"Que lá tem muitos colegas bons e também ruins [?uins] ${ }^{8 ”}$ (Alex).

"De ruim [?uim] ou de bom?" (Francis).

“Ah, preconceito racial [racial], de cor, preto, branco, e até por religião [?eligião]”. (Jandira).

As outras quatro ocorrências classificadas como intermediárias foram produzidas pelo mesmo estudante, durante a leitura do texto e na análise desta, etapas consecutivas da gravação da entrevista. O informante intercalou o uso da intermediária e do tepe em contextos de vibrante múltipla, como segue:

“O menino dos efes e erres [e?es]. O menino dos efes e erres [e?es] é o Orfeu Orofilo Ferreira [fereira]. Aí, com tantos fefê e rr erres, não erres [e?es]. [...] Não, só fala do menino dos efes e erres [e?es]. Acho que é o nome dele." (Marcos).

Embora tenhamos dados que nos mostram uma presença forte do fenômeno em variação na fala dos estudantes, já que o tepe é a variável utilizada em $75 \%$ dos contextos em que o esperado era uma vibrante múltipla, a presença da intermediária revela uma tentativa do informante de se aproximar da variedade de prestígio, possivelmente por influência de alguns dos colegas detentores desta variedade linguística. Considerando o que afirma Labov (2008 [1972]), podemos dizer que, no caso do estudante, a influência dos pares foi fundamental para a alteração de variedade linguística. De acordo com o autor: "Na grande maioria dos casos que temos estudado ou encontrado, as crianças seguem o padrão de seus pares. Posso citar muitos exemplos de minhas próprias observações, tanto

\footnotetext{
${ }^{7}$ Os nomes dos estudantes entrevistados foram substituídos por pseudônimos.

${ }^{8}$ Marcamos a produção de intermediária com /?/.
} 
quanto qualquer linguista que tenha investigado a matéria” (LABOV, 2008 [1972], p. 349).

Os dados gerais da Tabela 1 atestam nossa hipótese inicial de que, entre o grupo de estudantes, a variação característica da interferência do dialeto italiano sobre a fala em português é bastante acentuada, mesmo se tratando de um grupo de adolescentes e, ainda, de quinta ou sexta geração de imigrantes.

Em contextos de tepe (como em "parede"), essa foi a variante empregada em 98\% das ocorrências (557 produções). A vibrante múltipla, nesse contexto, foi registrada apenas 11 vezes, representando $2 \%$ do total das produções. Os casos de emprego da vibrante múltipla em contextos de tepe estão concentrados nas entrevistas de três estudantes do sexo feminino. Nesses registros, apenas um está em contexto de relatos do cotidiano, em um trecho no qual foi solicitado que simulassem um discurso de primeiro dia de aula no estabelecimento no qual estavam matriculados para iniciar o Ensino Médio em 2010, explicando como era a escola de onde vinham:

“Tá: lá no colégio eu morava [moRava] desde criança e eu estudei na Coca no Bairro [bairo] Belvedere desde o pré que eu estudava lá." (Jandira).

Dois dos casos de emprego de vibrante múltipla em contexto de tepe foram registrados em situação de leitura de texto, ambos na produção da palavra "Meireles", no sobrenome da autora do texto lido:

“Cecília Meireles [meiReles], Ou isto ou aquilo” (Diana).

“Cecília Meireles [meiReles], Ou isto ou aquilo” (Eduarda).

Oito empregos da vibrante múltipla em contextos de tepe estão em situações nas quais as estudantes avaliam a fala. Uma delas produz as vibrantes para exemplificar uma pronúncia que considera diferente daquela que faz parte da sua comunidade:

"Eu não me adaptaria muito fácil falando Ferreiro [feReiro], Orofilo [oRofilo], eu não conseguiria eu não iria entender, eu não saberia que era com erre [ere], né? Vou pensar, sei lá, agá, alguma coisa assim, né? Porque é diferente da gente, aqui” (Jandira, avaliação da fala).

É interessante observar a afirmação da estudante de que, em casos da produção da vibrante, perde a referência da grafia da palavra pronunciada: “[... ] eu não saberia que era com erre [ere], né? Vou pensar, sei lá, agá, alguma coisa assim, né?”, diz a estudante (Jandira).

Afirmações semelhantes aparecem sempre que os estudantes argumentam em defesa da variedade local como a mais coerente com "a grafia com erre": "Que nem 'caro', a 
gente fala 'caro' lendo mais o 'erre' e tem gente que fala 'carro' [caxº], mais com o agá', explica o estudante Elvis.

Como hipóteses para justificar esse posicionamento dos estudantes, podemos apontar o desconhecimento em relação ao elevado grau de poliformismo do fonema /r/. No português brasileiro, de acordo com Callou, Moraes e Leite (1996, p. 465) a variação na produção da vibrante se deve à amplitude do espaço articulatório existente para a realização desse segmento fônico, seja no grau de abertura no eixo vertical (vibrante ou fricativa, por exemplo), seja na área de articulação na dimensão longitudinal (alveolar, velar, uvular ou faríngeo, por exemplo) (CALLOU; MORAES; LEITE, 1996, p. 465). Ao ouvir uma fricativa, em vez de uma vibrante, especificamente de um tepe, os estudantes remetem ao "agá", uma letra "sem som". Outra hipótese pode ser a influência do aprendizado de inglês como língua estrangeira na escola. Possivelmente eles relacionem as produções de [caxo] e [xua] com as pronúncias de palavras inglesas iniciadas com agá, como "have", "home" e "house", por exemplo.

Identificamos, também, a dificuldade de entender qual o contexto para a produção de uma vibrante múltipla, na fala dos estudantes. Basta observar a produção da palavra "Ferreira", produzida por ela como "Ferreirra": "Os ff e erres [eRe] do Orofilo Ferreira [feReiRa], aí tem ff e erre [eRe], ferreira [feReiRa], coisas assim que se engana, né?” (Jandira). No caso da outra estudante (Eduarda), que utilizou a vibrante múltipla em contextos de tepe em situação de avaliação de fala, é interessante observar que isso se dá quando ela indica as advertências da tia em relação aos usos "errados" da família: "Na minha família também tem bastante erro [eRo] de português, como diz a minha madrinha, ela diz, que ela é de fora [foRa].” (Eduarda).

Adiante, ela repete o termo "diferente", com o emprego da vibrante múltipla, também se referindo ao que considera como problemas de pronúncia: “É, porque tem muitos nomes difíceis com $\mathrm{k}$ e y, diferente [difeRente] e a gente tem que pronunciar diferente [difeRente] e ali que o problema, mas com o tempo..." (Eduarda).

Na sequência da entrevista, quando questionada sobre o que considera ser o ideal em relação à pronúncia da vibrante múltipla (perguntamos sobre a pronúncia da palavra "carro"), ela faz um comentário que indica a questão da "norma” estabelecida pela comunidade, incluindo a escola:

\footnotetext{
${ }^{9}$ Usamos a marcação [x] para indicar a produção de uma fricativa velar na fala dos estudantes. Contextos como este, no qual a informante faz referência a uma variante com a qual não está habituada, são os únicos nos quais os estudantes usam a vibrante alveolar, confundida, como dia a estudante, com a pronúncia com "agá”.
} 
Entrevistadora: Como que você acha que deveria ser?

Eduarda: Carro [caro], como se for, só que na hora da leitura eu falo carro [caRo]. Entrevistadora: Daí os professores chamam a atenção, ou os colegas?

Eduarda: Mais os professores porque os colegas não tanto.

Entrevistadora: E eles dizem como?

Eduarda: Eles falam a palavra normal, assim.

Entrevistadora: Fala o normal, então?

Eduarda: Carro [caRo], caro [caro], caro [caro].

Entrevistadora: "Caro" seria o certo, então? Te chamam a atenção nesse sentido então?

Eduarda: Ah, ahm.

Ao contrário de pesquisas anteriores com a comunidade de descendentes de italianos com idade acima de 25 anos de Chapecó, a variação em contexto de tepe é, entre o grupo de adolescentes que constituem o corpus desta pesquisa, estatisticamente baixa. Poderíamos esperar resultados diferentes, já que se trata de público jovem e exposto à influência da mídia na produção linguística, o que poderia levar à hipercorreção. Importante destacar que todos os vinte estudantes participantes da pesquisa afirmaram ter em casa acesso ao rádio e à televisão; dezoito a telefone celular; treze a telefone fixo; oito disseram possuir computador; e, entre eles, cinco com conexão à internet. Um dos adolescentes, ao ser levado a avaliar a diferença na produção da vibrante entre a comunidade onde vive e outros locais, fez a seguinte colocação:

Leonardo: O nosso é erre [eRe] (faz uma vibrante ápico dental), erre [ere]e eles falam erre $[\mathbf{e} \mathbf{R e}]$.

Entrevistadora: E onde que fala assim?

Leonardo: É tipo mais para a cidade que eles falam assim. Eu gosto de assistir os filmes... [não concluiu a frase]

Entrevistadora: E por que a gente fala diferente o erre, por exemplo?

Lreonardo: Ah...

Entrevistadora: Tem a ver com família, com cultura?

Leonardo: Acho que tem a ver com família, a gente aprende falar com o pai, com a mãe, a gente aprendeu assim, já está acostumado.

Embora ampliemos essa discussão adiante, ao tratar da interferência das variáveis extralinguísticas no fenômeno em variação, é preciso considerar, aqui, o fato de o grupo 
viver em comunidades rurais (nove estudantes) e em dois bairros da periferia, distantes cerca de 10 quilômetros do centro da cidade (11 estudantes). Pode-se avaliar, então, que sofre baixa pressão social para adequar-se à variedade de prestígio. A pesquisa desenvolvida por Spessatto (2001) com falantes da mesma comunidade, adultos acima de 25 anos, considerou um grupo de falantes urbanos e, via de regra, inseridos no mercado de traba1ho. Embora entre esses falantes o percentual de tepe em contextos de vibrante múltipla tenha sido alto (46\%), a análise dos dados feita pela pesquisadora indicou uma incidência um pouco mais acentuada de vibrante múltipla em contextos de tepe (4,5\%), além da significativa presença da intermediária (registrada em 35\% dos contextos de vibrante múltipla), evidenciando a tentativa dos informantes de aproximação com a variedade de prestígio, o que não parece ocorrer com o grupo de informantes que constitui o corpus desta pesquisa. Eles, como já informamos anteriormente, produziram tepe em $75 \%$ dos casos nos quais o esperado era uma vibrante múltipla.

A baixa pressão social em direção a uma mudança linguística entre o grupo pode estar relacionada às redes sociais estabelecidas entre eles. Essas redes estão relacionadas à dinâmica de comportamentos interacionais entre indivíduos. Para explicá-las, afirma Monguilhott (2009, p. 52), devemos olhar para suas associações diárias, investigando como as pessoas se conhecem e como fazem para se conhecer.

Quanto maior o número de pessoas que se conhecem em uma rede, maior sua densidade (número de ligações entre os indivíduos em uma rede). Redes multiplexas são compostas por indivíduos que se relacionam entre si em diversas condições (parentes, vizinhos, trabalho, lazer). Já a rede uniplexa é caracterizada por indivíduos que se relacionam de uma única maneira. (MONGUILHOTT, 2009, p. 52).

No caso aqui apresentado, embora tenha sido feita uma análise detalhada das redes sociais estabelecidas entre os estudantes, os dados gerais das fichas sociais preenchidas por eles ao longo do trabalho de pesquisa de campo ${ }^{10}$ indicam o convívio diário entre a maioria deles também em ambientes externos à escola, nos turnos nos quais não estão em sala de aula.

Retomando os dados linguísticos dos estudantes, observamos que, em relação à posição na palavra, 98\% das produções em contextos de tepe (posição intervocálica como em "parede") ocorreram com o emprego dessa variante e apenas $2 \%$ foram de vibrante múltipla, como já indicado na análise da tabela de distribuição geral das ocorrências. $O$

\footnotetext{
${ }^{10}$ Em etapa anterior do estudo que deu origem a este artigo.
} 
percentual de uso do tepe em início de palavra foi de $80 \%$ e apenas $18 \%$ das ocorrências nesse contexto foram de /R/, variante esperada. Fazendo a análise percentual geral, observa-se uma leve vantagem na posição início de palavra (80\%) sobre a intervocálica de vibrante múltipla (74\%) para a produção de tepe. Para a produção da intermediária, também há pouca diferença em relação ao contexto: $2 \%$ dos casos foram em início de palavra e $1 \%$ em contexto de intervocálica de vibrante múltipla.

A partir do que os dados apresentados pela primeira rodada foram nos mostrando, optamos por desconsiderar a intermediária, devido à recorrência percentualmente baixa e bastante localizada. As sete ocorrências da variável "intermediária” foram produzidas por apenas três estudantes, conforme explicitado anteriormente. Desta forma, desconsiderando a "intermediária", temos a seguinte distribuição geral dos dados:

Tabela 2 - Dados gerais das produções do fonema vibrante, desconsiderando a variante intermediária

\begin{tabular}{|l|lr|rc|c|}
\hline & \multicolumn{2}{|c|}{$\begin{array}{l}\text { Vibrante } \\
\text { múltipla }\end{array}$} & \multicolumn{2}{c|}{ Tepe } & Total \\
\hline $\begin{array}{l}\text { Contexto esperado de vibrante } \\
\text { múltipla ("rua" e "carro") }\end{array}$ & $\begin{array}{l}\text { Freq. } \\
124\end{array}$ & $\begin{array}{c}\% \\
24\end{array}$ & $\begin{array}{l}\text { Freq. } \\
394\end{array}$ & $\begin{array}{c}\% \\
76\end{array}$ & 522 \\
\hline $\begin{array}{l}\text { Contexto esperado de tepe } \\
\text { ("parede") }\end{array}$ & 11 & 2 & 571 & 98 & 571 \\
\hline TOTAL & 135 & 12 & 959 & 88 & $\mathbf{1 . 0 9 4}$ \\
\hline
\end{tabular}

Fonte: Spessatto (2011, p. 156).

Desconsideradas as produções da variante intermediária, foram constituídos os dados a serem utilizados nas rodadas seguintes, nas quais passou a ser controlado, também, o peso relativo que mede probabilisticamente a interferência das variáveis linguísticas e extralinguísticas nas produções do fenômeno em análise. Diante de um quadro que nos revela uma significativa variação em contextos de vibrante múltipla, no qual a maioria significativa das ocorrências é de tepe, optamos por analisar quantativamente a variação apenas nesse contexto. Das 522 produções nas quais era esperada a realização de uma vibrante múltipla, 124 , representando $24 \%$ das ocorrências, foram da variante esperada, enquanto que 398 ocorrências, representando $76 \%$, foram de tepe.

\section{Análise geral de produções de tepe em contextos de vibrante múltipla}

As tabelas que fazem parte desta seção apresentam os grupos de fatores que foram apontados pelo Programa VARBRUL como os mais significativos estatisticamente para 
as realizações de vibrante múltipla e de tepe em contextos de vibrante múltipla (como em "rua" e "carro" [522 dados]). Na rodada geral, que mede a relevância de todas as variáveis sociais e linguísticas para as produções em todos os contextos, apenas dois grupos de fatores foram selecionados, nesta ordem: a produção de cada informante (variação na fala de cada um dos 20 estudantes) e o contexto estilístico da entrevista (relatos do cotidiano, leitura e avaliação da fala ${ }^{11}$. Abaixo, apresentamos a tabela com a descrição das produções dos 20 estudantes. Ao lado da frequência de produção, apresentamos os percentuais e os pesos relativos para a produção de tepe em contexto de vibrante múltipla, com exceção dos quatro primeiros indivíduos, cujos pesos relativos não foram gerados pelo programa, por terem produzido $100 \%$ de tepe em contextos esperados de vibrante múltipla, como segue:

Tabela 3 - Distribuição dos usos de tepe em contexto esperado de vibrante múltipla, por informante

\begin{tabular}{|l|lll|}
\hline & $\begin{array}{c}\text { Freq. } \\
\text { Aplic/Total }\end{array}$ & $\%$ & PR \\
\hline Débora & $28 / 28$ & 100 & - \\
\hline Fernando & $58 / 58$ & 100 & - \\
\hline Juliano & $58 / 58$ & 100 & - \\
\hline Luís & $49 / 49$ & 100 & - \\
\hline Carlos & $35 / 37$ & 95 & 0,86 \\
\hline Marcos & $15 / 16$ & 94 & 0,77 \\
\hline Jana & $39 / 44$ & 89 & 0,77 \\
\hline Elvis & $24 / 26$ & 92 & 0,76 \\
\hline Leonardo & $22 / 25$ & 88 & 0,75 \\
\hline João & $16 / 18$ & 89 & 0,70 \\
\hline Francis & $10 / 11$ & 91 & 0,69 \\
\hline Túlio & $19 / 23$ & 83 & 0,58 \\
\hline Lauro & $22 / 26$ & 85 & 0,56 \\
\hline Suzana & $17 / 21$ & 81 & 0,53 \\
\hline Ana & $18 / 21$ & 86 & 0,52 \\
\hline Diana & $39 / 52$ & 75 & 0,48 \\
\hline Jandira & $17 / 28$ & 61 & 0,35 \\
\hline Denis & $08 / 23$ & 35 & 0,18 \\
\hline Eduarda & $04 / 27$ & 15 & 0,06 \\
\hline Alex & $04 / 35$ & 11 & 0,02 \\
\hline & $398 / 522$ & & \\
\hline & & & \\
\hline & TOTAL & 93 & \\
\hline
\end{tabular}


Fonte: Spessatto (2011, p. 157).

Analisamos as fichas sociais dos informantes que produziram $100 \%$ de tepe em contextos de vibrante múltipla e encontramos as seguintes características sociais: uma é do sexo feminino e três do sexo masculino, dois vivem na área urbana e dois na rural, dois dizem-se bilíngues e dois monolíngues.

A primeira informante, Débora, vive na área urbana e é monolíngue, falante apenas do português brasileiro. Estudou na escola, inserindo-se na turma de sujeitos analisados nesta pesquisa apenas no último ano do ensino fundamental e não fez referência, na ficha social, a relações mais estreitas com colegas de classe. Entretanto, sempre morou em um bairro localizado próximo à escola e, por isso, desde a infância está vinculada à comunidade. Já o outro falante monolíngue e urbano que produziu 100\% de tepe (Luís) aponta estreito vínculo com os outros dois informantes com as mesmas características linguísticas (Fernando e Juliano). Luís estudou na escola desde a quarta série do ensino fundamental, portanto, tem uma relação de quatro anos com os colegas de classe.

As características sociais dos outros dois estudantes (Fernando e Juliano) são bastante parecidas: ambos são habitantes da área rural e bilíngues. Também se indicam, mutuamente, como as referências de atividades extraescolares, quando questionados sobre os vínculos com os colegas de classe, nas fichas sociais preenchidas em outubro de 2009. Entretanto, dentre as características sociais desses quatro informantes, o que os une é a etnicidade. Todos são descendentes de italianos e estão expostos, com mais ou menos frequência, à fala dialetal italiana, mesmo aqueles que se caracterizaram como monolíngues. Os dois informantes que estão nessa condição apontaram, em entrevistas e fichas sociais, o reconhecimento de alguns itens lexicais, como "cuciaro" (colher), è vero (é verdade)" (Luís, ficha social preenchida em outubro de 2009); e o contato com tios e avós que “[...] só ficam falando [dialeto] e eu não entendo muita coisa” (Débora, entrevista gravada em abril de 2009). Os outros dois estudantes que produziram $100 \%$ de tepe, além de informarem serem bilíngues, afirmaram a exposição à fala dialetal "praticamente sempre" (Fernando) e "a toda hora” (Juliano).

Com exceção de apenas três estudantes que produziram baixos percentuais de tepe (35\%, 15\% e 11\%), entre os demais estudantes da turma, cujas produções linguísticas estão apresentadas na tabela anterior, o percentual de produção de tepe em contextos de vibrante múltipla ficou acima de $60 \%$, sendo que 11 produziram mais de $80 \%$ de tepe em

${ }^{12}$ Forma dialetal descrita por Luzzatto (2000, p. 98). Nardo (2010, p. 214) grafa o termo como "guciaro". No italiano oficial, "cucchiaio". 
contextos de vibrante múltipla, quatro deles com produções de tepe em mais de $90 \%$ das ocorrências linguísticas: Carlos, com 95\%; Marcos, com 94\%; Elvis, com 92\%; e Francis, com 91\%. Dos quatro, três são monolíngues (Carlos, Marcos e Francis) e apenas um bilíngue (Elvis); dois moram na área rural (Carlos e Francis) e dois na periferia da área urbana (Marcos e Elvis). Diante de dados como esses, julgamos importante considerar os vínculos estabelecidos na comunidade e reforçados na escola.

Todos os estudantes vivem nas proximidades do estabelecimento no qual estudam e é nos arredores que acontecem as festas comunitárias e os eventos sociais dos quais todos participam. Mesmo aqueles que vivem nos bairros encontram na área rural a referência para as atividades culturais. O salão da igreja da comunidade, situada ao lado da escola, é o espaço no qual se realizam as festas e até algumas atividades extracurriculares das quais participam os estudantes, como as aulas de dança italiana. A distância do centro da cidade, de mais de dez quilômetros, faz com que todos se sintam integrados e compartilhem sentimentos comunitários ${ }^{13}$.

Por outro lado, do grupo de 20 estudantes que constituem o corpus de análise, apenas três apresentam uma frequência alta de produção da vibrante múltipla em contextos esperados: os informantes Alex ( $89 \%$ das produções como vibrante múltipla e $11 \%$ como tepe), Eduarda ( $85 \%$ de vibrantes múltiplas e 15\% de tepes) e Denis (65\% de vibrante múltipla e $35 \%$ de tepes).

O estudante que menos produziu o tepe, Alex, veio da capital do estado e vivia, na época da coleta de dados, há quatro anos em um dos bairros próximos à escola, ingressando no estabelecimento apenas no último ano do ensino fundamental. $\mathrm{O}$ caso é semelhante ao de Denis, também vindo da grande Florianópolis, porém, no período já há seis anos na comunidade e há dois estudando na escola. Ambos são moradores urbanos e monolíngues. Eles foram os únicos entre os estudantes a revelar o reconhecimento de que a comunidade fala uma variedade desprestigiada, sujeita a preconceito quando empregada fora do contexto no qual passaram a se inserir: "Ah, vão tirar sarro [saRo] de mim”, afirmou Alex, ao ser questionado em relação ao modo como seria recebido em sua cidade natal, se voltasse usando a variedade da sua nova comunidade; "Ah, vão dar risada [Risada], no mínimo", concluiu Denis, diante da mesma questão.

Entretanto, é evidente, por parte dos dois estudantes, a tentativa de se sentirem incluídos na comunidade, também pela questão linguística. Ambos afirmaram procurar

\footnotetext{
13 A pesquisa que deu origem a este trabalho permitiu identificar que há, na escola em análise, um reforço das características comunitárias e étnicas. Observamos durante o desenvolvimento do estudo a valorização das características comunitárias na voz dos estudantes. Há uma forte noção de "pertencimento" (BAUMAN, 2003; MILROY, 1980 apud MONGUILHOTT, 2009).
} 
aproximar-se do modo de falar local: “É, puxo mais para o lado de cá, agora, de Chapecó. Mas três anos atrás era meio manezinho ${ }^{14}$, ainda. [...] Eu até que estranhei, mas tinha que falar do jeito que eles falam, se não eles tiram sarro [saRo]" (Alex); "Eu achava engraçado. Eles também davam risada [Risada] de mim, mas depois [...] mudei, sei lá, porque acostumei. Estou com eles direto e aí se acostuma” (Denis).

Diferente dos dois estudantes, a informante Eduarda, que produziu $85 \%$ de vibrante múltipla em contextos esperados, nasceu no mesmo bairro em que mora e estudou na escola em seis dos oito anos do ensino fundamental. Outra diferença é o fato de apresentar-se como bilíngue. Quando avaliou a própria fala e a da comunidade, afirmou que "na minha família tem bastante erros [eRos]", atribuindo à madrinha, professora "que é de fora [foRa]", a explicação. Afirmou, também, estar sendo orientada por essa pessoa a modificar o modo de falar, para inserir-se no mercado de trabalho: "E pra mim começar no Senac ela também me ajudou bastante nos meus erros [eRos] ela me ajudou bastante”.

Como segundo grupo de fatores significativos que favorecem a produção de tepe em contextos de vibrante múltipla, foi selecionado pelo programa VARBRUL o contexto estilístico da entrevista. Como analisamos, neste trabalho, a relação da escola com uma variedade linguística desprestigiada, caracterizada pela não produção da vibrante múltipla em contextos esperados pelo padrão fonológico do português brasileiro, julgamos interessante invertermos a tabela e avaliarmos, também, a interferência do contexto estilístico da entrevista na produção da vibrante múltipla em contextos esperados, relacionando o aumento do grau de monitoramento do contexto estilístico na produção da variante de mais prestígio social. Dessa forma, na tabela que segue, apresentamos os dados dos dois contextos (de tepe e de vibrante múltipla), comparativamente, para facilitar a visualização:

Tabela 4 - influência do contexto estilístico da entrevista na produção de tepe e de vibrante múltipla, ambos em contexto de vibrante múltipla

\begin{tabular}{|l|ccl|lcc|}
\hline & \multicolumn{3}{|c|}{ Tepe } & \multicolumn{3}{c|}{ Vibrante múltipla } \\
\hline Contexto estilístico & $\begin{array}{c}\text { Freq. } \\
\text { Aplic./total }\end{array}$ & $\%$ & PR & Aplic./total & $\%$ & PR \\
\hline Relatos & $125 / 142$ & 88 & 0,68 & $17 / 142$ & 12 & 0,32 \\
Leitura & $167 / 215$ & 78 & 0,57 & $22 / 215$ & 22 & 0,43 \\
Avaliação & $106 / 165$ & 64 & 0,27 & $36 / 16$ & 36 & 0,73 \\
Total & $398 / 522$ & $\mathbf{7 6}$ & & $124 / 522$ & $\mathbf{2 4}$ & \\
\hline
\end{tabular}

Fonte: Spessatto (2011, p. 161). 
De acordo com o que mostra a tabela, o contexto estilístico de relatos do cotidiano é o que mais estimula o emprego do tepe ( $88 \%$ e 0,68 de peso relativo). A leitura é o contexto estilístico mais neutro, onde há menos variação, com um peso relativo próximo a 0,50 (78\% de produções). Por outro lado, a situação de avaliação da fala é o que mais inibe a produção do tepe em contextos de vibrante múltipla, com peso relativo de 0,27 (64\% dos casos). Em contrapartida, observamos que quanto mais o grau de monitoramento aumenta, mais cresce a produção da vibrante múltipla em contextos esperados para essa variante. Embora os percentuais de produção da variante vibrante múltipla em contexto de avaliação (+ monitorado) apresentem-se ainda inferiores ao de produção do tepe nesses contextos (somando 36\%), temos aí um acréscimo de 24 pontos percentuais na produção do fonema, se comparado ao contexto estilístico de relatos do cotidiano. Com esses dados, poderíamos dizer que há uma intervenção escolar levando à compreensão de que o aumento do grau de monitoramento requer o emprego da vibrante múltipla em contextos esperados.

Entretanto, os resultados precisam ser relativizados mediante as circunstâncias encontradas nas produções de muitos estudantes nesses contextos estilísticos. Eles foram levados a refletir sobre a diferença de pronúncia de palavras como "carro" e "caro". Dessa forma, o emprego da vibrante múltipla em contextos de avaliação de fala nem sempre pode ser interpretado como uma preocupação do falante em se aproximar da variedade de prestígio, como mostra o exemplo abaixo. $\mathrm{O}$ estudante produtor do enunciado empregou, em toda a entrevista, apenas duas vezes a vibrante múltipla, ambas em situação de avaliação, como segue:

Entrevistadora: E se a gente falasse assim "carro" ou "caro", que diferença tem?

Elvis: Aqui a gente fala mais "caro [caro]", né? E depende também da pessoa como ela consegue falar. Tem gente aqui em Chapecó que fala "carro [caRo]", tem gente que é "caro [caro]", bastante. [...] a gente fala "caro" lendo mais o erre [ere] e tem gente que fala "carro [caRo]", mais com o agá.

O mesmo ocorre com outro informante que, ao longo de toda a entrevista, produziu apenas duas vezes a vibrante múltipla, ambas em contexto de avaliação de fala. Depois da leitura do texto, foi questionado sobre as diferenças de produção do fonema vibrante:

Entrevistadora: Tem gente que fala "Ferreira", tem outros que falam "Fereira", você já percebeu essa diferença? 
[... Carlos: Sim, tem gente que fala a mesma coisa que os efes. Ferreira [feReira], fala o erre [ere] em tom mais alto ou em tom mais baixo.

Como já afirmamos, diante de casos como esses, é preciso considerar que nem sempre há, por parte dos estudantes, o reconhecimento da variação como um fator de avaliação social. A produção da vibrante, nos casos acima, se dá por reprodução e não por produção voluntária, sendo que isso ocorre, também, com algumas produções da vibrante múltipla em outros informantes, como os casos citados na seção anterior (nas falas das estudantes Eduarda e Jandira). No caso da estudante Jandira, esta também associa, como já apresentamos, a produção de /R/ com "palavras com agá".

Como a variável independente 'contexto estilístico' se mostrou estatisticamente relevante no favorecimento/inibição da produção de tepe em contextos de vibrante múltipla, resolvemos efetuar rodadas diferenciadas para cada contexto, com vistas a avaliar melhor o comportamento linguístico dos informantes. Em relação ao contexto estilístico de relatos do cotidiano, que mais favorece a produção de tepe em contextos de vibrante múltipla, nenhuma das demais variáveis linguísticas ou extralinguísticas foi selecionada como significativa para as produções de tepe em contextos de vibrante múltipla. Esse resultado reforça a hipótese de que a variedade local é detentora de prestígio na comunidade, não havendo preocupação dos falantes em mudar a forma, quando na fala cotidiana. Assim, as seções a seguir se destinam à apresentação e discussão desses resultados mais específicos, voltados aos contextos de leitura e avaliação da fala.

\section{A produção de tepe em contextos estilísticos de leitura}

Em contextos estilísticos de leitura, duas variáveis independentes foram selecionadas como significativas, uma extralinguística, a área de moradia' e outra linguística, a 'posição na palavra', nessa ordem de significância. Analisamos, primeiramente, a influência da área de moradia na produção da variante, conforme tabela abaixo:

Tabela 5 - Influência do local de moradia na produção de tepe em posição de vibrante múltipla em contextos estilísticos de leitura

\begin{tabular}{|l|ccc|}
\hline & $\begin{array}{c}\text { Freq. } \\
\text { Aplic./total }\end{array}$ & $\%$ & PR \\
\hline Rural & $73 / 80$ & 91 & 0,75 \\
Urbano & $94 / 135$ & 70 & 0,32 \\
Total & $167 / 215$ & & \\
\hline
\end{tabular}


Fonte: Spessatto (2011, p. 163).

A Tabela 5 mostra uma acentuada tendência dos estudantes residentes na área rural de produção do tepe em contextos de vibrante múltipla. Entre os dados linguísticos desses informantes nos contextos estilísticos de leitura, $91 \%$ das ocorrências foram de tepe (peso relativo de 0,75 ). Por outro lado, o peso relativo de 0,32 (70\%) para a produção do tepe nesse contexto mostra que há uma inibição desse uso entre falantes urbanos.

A tabela abaixo exibe os resultados para a variável 'posição na palavra' ${ }^{15}$ :

Tabela 6 - Influência da variável linguística posição na palavra na produção de tepe em posição de vibrante múltipla em contextos estilísticos de leitura

\begin{tabular}{|l|ccc|}
\hline & $\begin{array}{c}\text { Freq. } \\
\text { Aplic./total }\end{array}$ & $\%$ & $\mathrm{PR}$ \\
\hline Intervocálica /R/ "carro" & $161 / 203$ & 79 & 0,53 \\
Início de palavra "rua" & $6 / 12$ & 50 & 0,21 \\
\hline
\end{tabular}

Fonte: Spessatto (2011, p. 164).

De acordo com os dados apresentados acima, a posição intervocálica é o contexto mais propício para a produção do tepe em contextos de vibrante múltipla, quando a variante em análise encontra-se em contexto estilístico de leitura. Nessa posição, 79\% das produções foram de tepe. Por outro lado, o contexto de início de palavra parece inibir a produção de tepe $(0,21)$.

\section{A produção de tepe em contextos estilísticos de avaliação da fala}

Em contextos estilísticos de avaliação, apenas a variável extralinguística sexo foi selecionada como significativa pelo programa. Os resultados são apresentados na tabela abaixo:

Tabela 7 - A influência da variável extralinguística sexo na produção de tepe em posição de vibrante múltipla em contexto estilístico de avaliação da fala

\begin{tabular}{|l|ccc|}
\hline & $\begin{array}{c}\text { Freq. } \\
\text { Aplic./total }\end{array}$ & $\%$ & PR \\
\hline Masculino & $65 / 88$ & 74 & 0,60 \\
Feminino & $41 / 77$ & 53 & 0,38 \\
\hline
\end{tabular}

Fonte: Spessatto (2011, p. 164). 
Observa-se um significativo favorecimento da produção de tepe entre os informantes do sexo masculino (peso relativo de 0,60 e 74\%). Já entre as meninas, há uma inibição do uso da variante. É preciso considerar que, mesmo o emprego do tepe em contexto de vibrante múltipla sendo o mais usual entre o grupo, representando $76 \%$ do total de ocorrências, o contexto em análise é o de avaliação da fala. Esse é o contexto estilístico mais monitorado, o que contribui para explicar o fato de serem as meninas as que mais controlam o uso, aproximando-se da variedade prestigiada. Estudos de variação, em geral, têm mostrado que, tradicionalmente, os falantes do sexo feminino tendem a se aproximar mais da norma padrão do que os falantes do sexo masculino, quando a variante que está em jogo é estigmatizada. Tal postura costuma ser explicada pela forma com que homens e mulheres vivem na sociedade, em especial pelo maior formalismo associado aos papéis femininos, como na educação dos filhos, por exemplo. Ou ainda pelo que Labov (2008 [1972]) denomina de prestígio encoberto, no caso em que os homens estão mais sujeitos a fazer uso de formas linguísticas que são socialmente desvalorizadas, desde que garantam sua identidade em um determinado grupo social.

Possivelmente o contexto de avaliação da fala tenha estimulado o controle por parte dos informantes, especialmente das meninas. Porém, vale relembrar que muitas das produções de vibrante múltipla em contextos esperados (como em "carro") se deu mais por reprodução do que por reconhecimento do valor social mais elevado dessa variante /R/, já que, inclusive, alguns dos estudantes classificam essas produções como "palavras com agá”.

Mesmo o local de moradia não tendo sido apontado pelo programa VARBRUL como significativo para as produções de tepe em contextos de vibrante múltipla no contexto estilístico em análise, julgamos importante avaliar o que os dados nos mostram acerca da influência desse contexto, como indica a tabela abaixo:

Tabela 8 - A influência da variável extralinguística local de moradia na produção de tepe em contextos estilísticos de avaliação da fala

\begin{tabular}{|c|ccc|}
\hline & \multicolumn{3}{|c|}{ Freq. } \\
& Aplic./total & $\%$ & PR \\
\hline Rural & $46 / 66$ & 70 & $(0.56)^{16}$ \\
Urbano & $60 / 99$ & 61 & $(0,46)$ \\
\hline
\end{tabular}

Fonte: Spessatto (2011, p. 165).

\footnotetext{
${ }^{16}$ Quando, nas tabelas, os pesos relativos aparecem entre parênteses é porque não foram considerados significativos pelo programa VARBRUL e foram tirados do nível 1.
} 
A tabela indica que, em contextos estilísticos de avaliação da fala, os informantes da área urbana inibem a produção da variante estigmatizada (tepe em contextos de vibrante múltipla), com um percentual de $61 \%$ das produções, contra $70 \%$ dos informantes residentes na área urbana. Embora com dados estatísticos ainda altos de produção da variante estigmatizada entre os informantes dos dois grupos sociais, podemos dizer que os dados se aproximam do que indicam as pesquisas sociolinguísticas que mostram a tendência dos informantes da área urbana de se aproximarem mais das variedades linguísticas mais prestigiadas.

\section{Considerações finais}

A análise dos dados estatísticos confirmou nosso pressuposto inicial de alta incidência de uso do tepe em contextos de vibrante múltipla ("carro") e também o uso praticamente categórico de tepe em contextos esperados ("parede"). Identificou-se a variação de uso entre os informantes (com uso de 100\% de tepe em contexto de vibrante múltipla) em quatro deles e um baixo uso dessa variante em apenas três estudantes (com 35\%, 15\% e 11\%). Outros fatores linguísticos ou extralinguísticos não se mostraram estatisticamente significativos para as produções, o que sugere a apropriação da variante étnica pelos falantes, não revelando a interferência da escola em direção a um padrão fonológico do português brasileiro. Muito embora tenhamos, quantitativamente, identificado a variável contexto estilístico como a mais significativa para a produção da vibrante múltipla em contextos esperados, nesse caso os estudantes foram levados a refletir sobre a diferença de pronúncia de palavras em questão ("carro" e "caro"). Assim, o emprego da variante esperada em contextos de avaliação de fala nem sempre pode ser interpretado como uma preocupação do falante em se aproximar da variedade de prestígio.

De modo geral, a análise dos dados nos revela a manutenção de características linguísticas que marcam o grupo étnico em análise, mesmo sendo os sujeitos da pesquisa indivíduos de faixa etária jovem e com acesso às variedades de prestígio da língua, seja por estarem frequentando a escola ou pela influência dos meios de comunicação. Os dados são significativamente expressivos, quando considerada a estigmatização dessas características linguísticas ao longo dos tempos, pelo "sentimento de vergonha do ítalo-brasileiro em relação ao seu modo de falar, seja em língua italiana ou em português regional" (FROSI, 2001, p. 256). Ainda, é preciso considerar o reconhecimento desse estigma entre o próprio grupo de estudantes, quando solicitados a avaliar como seriam 
recebidos em sua cidade natal, se voltassem usando a variedade linguística da sua nova comunidade: "Ah, vão tirar sarro [saRo] de mim" (Alex); "Ah, vão dar risada [Risada], no mínimo” (Denis).

Os resultados identificados neste trabalho revelam, seja pelos dados quantitativos, seja nas entrelinhas dos depoimentos dos jovens sujeitos ouvidos, a persistência com que sobrevivem as línguas minoritárias, mesmo que seja se fazendo presentes em interferências nos usos da língua oficial. Os imigrantes e seus descendentes, que vieram ao Brasil para atender às demandas por mão de obra e para contribuir com a manutenção do território nacional em regiões de fronteira, foram obrigados a abandonar suas línguas de origem, especialmente durante a Campanha de Nacionalização, na década de 1930. A partir daí, bastou um passo para sofrerem o estigma de não serem detentores do português: "Eles [filhos] não querem que eu ensine. Dizem: 'Ih, mãe, essa língua ali nem fale com nós. Não adianta. Nós não podemos depois falar com os outros. Eles não entendem, eles dão risada”. (Informante 01, Banco de Dados VARSUL apud SPESSATTO, 2001, p. 36).

Se temos, independente de todos esses fatores em contrário, a preservação das características linguísticas que marcam o grupo, valerá a pena pensarmos, em futuros estudos, em aspectosrelacionadosàlínguaeidentidade,nãoapenasparajustificarmosessesusos, maspara trazermos à tona o debate, sempre atual, acerca da diversidade que marca o povo brasileiro.

\section{Referências}

BALHANA, Altiva Pilatti. Presenza di comunità dialettali italiane in Brasile: aspetti sociali, economici e demografici. In: LO CASCIO, Vincenzo (a cura di). L'italiano in America Latina. Firenze: Felice le Monnier, 1987.

BERETTA, Pier Luigi. Notizie di geografia ambientale ed umana sugli insendiamentiveneti nel Rio Grande do Sul. In: ZILIO, Giovanni Meo. Presenza, cultura, lingua e tradizioni dei veneti nel mondo - parte I America Latina. Venezia: Guinta Regionale Veneto, 1987.

CALLOU, Dinah; MOARES, João A.; LEITE, Yonne. Variação e diferenciação dialetal: a pronúncia do /R/ no português do Brasil. In: KOCH, Ingedore G. Villaça. Gramática do português falado. Campinas/SP: UNICAMP, 1996.

CORRÀ, Loredana. I veneti in Brasile: koinè dialettale come superamento dei confini? In: MARCATO, Gianna (a cura di). I confini del dialetto. Padova: Unipress, 2001.

CORRÀ, Loredana. Il “talian” dei veneto-brasiliani. In: MARCATO, Gianna (a cura di). Italiano: strana lingua?. Padova: Unipress, 2003.

COSTA, Rovilio; DE BONI, Luis Alberto (a cura di). La presenza italiana nella storia e nella cultura del Brasile. Torino: Fondazione Giovanni Agnelli, 1991. 
FRANZINA,Emilio.L'America degliemigranti: dal Veneto ai "nuovimondi"latinamericani (1876-1924). In: ZILIO, Giovanni Meo. Presenza, cultura, lingua e tradizioni dei veneti nel mondo - parte I America Latina. Venezia: Guinta Regionale Veneto, 1987.

FROSI, Vitalina. Interrelazioni fra il dialeto veneto e la lingua portoghesebrasiliana. In.: ZILIO, Giovanni Meo. Presenza, cultura, lingua e tradizioni dei veneti nel mondo - parte I America Latina.Venezia: Guinta Regionale Veneto, 1987a.

FROSI, Vitalina. I dialetti italiani nel Rio Grande do Sul e il loro sviluppo nel contesto socio-culturale ed economico: prevalenza del dialetto veneto. In.: LO CASCIO, Vincenzo (a cura di). L'italiano in America Latina. Firenze: Felice le Monnier, 1987b.

FROSI, Vitalina. L'italiano standard e i dialetti italiani in Brasile. In.: MARCATO, Gianna (a cura di) I confini del dialetto. Padova: Unipress, 2001.

FROSI, Vitalina; MIORANZA, Ciro. Dialetos italianos: um perfil lingüístico dos ítalobrasileiros do Nordeste do Rio Grande do Sul. Caxias do Sul: Educs, 1983.

LABOV, William. Padrões Sociolinguísticos. São Paulo: Parábola, 2008 [1972].

LO CASCIO, Vincenzo (a cura di). L'italiano in America Latina. Firenze: Felice le Monnier, 1987.

LUZZATTO, Darcy Loss. Dissionàrio Talian-vêneto brasileiro-português. Porto Alegra: Saga Luzzatto, 2000.

MARCATO, Gianna (a cura di) I confini del dialetto. Padova: Unipress, 2001.

MARGOTTI, Felício W. Difusão sócio-geográfica do português em contato com o italiano no Sul do Brasil. 2004. 332 f. Tese (Doutorado em Letras), Programa de Pós-graduação em Letras. Universidade Federal do Rio Grande do Sul, Porto Alegre, 2004.

MEIRELES, Cecília. Ou isto ou aquilo. $5^{\text {a }}$ ed. Rio de Janeiro: Nova Fronteira, 1990.

MOLLICA, Maria Cecília (org). Introdução à Sociolingüística Variacionista. Rio de Janeiro: Cadernos Didáticos UFRJ, 1992.

MONGUILHOTT, Isabel de Oliveira e Silva. Estudo sincrônico e diacrônico da concordância verbal de terceira pessoa do plural no PB e no PE. 2009. 229f. Tese de Doutorado (Programa de Pós-graduação em Linguística), Universidade Federal de Santa Catarina, Florianópolis, 2009.

NARDO, Luigi. Dizionario Italiano-Veneto: a sercar parole. Padova: Editoriale Programma, 2010 .

OLIVEIRA e SILVA, Gisele M.; SCHERRE, Maria Marta P. (org.) Padrões sociolingüísticos. Rio de Janeiro: Tempo Brasileiro, 1996.

PETRONE, Paquale. Italiani e discendenti di italiani in Brasile: le scuole e la lingua. In: COSTA, Rovilio; DE BONI, Luis Alberto (a cura di). La presenza italiana nella storia e nella cultura del Brasile. Torino: Fondazione Giovanni Agnelli, 1991.

PINTZUK, Susan. VARBRUL programs - versão 2s. 1988. (mimeo) 
SPESSATTO, Marizete B. Marcas da história: características dialetais na fala dos descendentes de italianos de Chapecó. 2001. 102 f. Dissertação de Mestrado (Programa de Pós-graduação em Linguística, Universidade Federal de Santa Catarina, Florianópolis, 2001.

SPESSATTO, Marizete Bortolanza. Variação linguística e ensino: por uma educação linguística democrática. 2011.231 f. Tese de doutoramento (Programa de Pós-graduação em Educação), Universidade Federal de Santa Catarina, Florianópolis, 2011.

ZILIO, Giovanni Meo. Presenza, cultura, lingua e tradizioni dei veneti nel mondo - parte I America Latina. Venezia: Guinta Regionale Veneto, 1987.

Data de submissão: $31 / 08 / 2020$

Data de aceite: 19/01/2021

(c) $)(1) \Theta$ 